\title{
Contribution of autochthonous yeasts with probiotic potential to the aroma profile of fermented Guajillo pepper sauce
}

Carlos Lara-Hidalgo a,b, Carmela Belloch a , Lidia Dorantes-Alvarez ${ }^{\text {b }}$, Mónica Flores ${ }^{a}$

\author{
aInstituto de Agroquímica y Tecnología de Alimentos (IATA-CSIC) Avda, Agustín Escardino 7, 46980 \\ Paterna, Valencia, España \\ bInstituto Politécnico Nacional, Escuela Nacional de Ciencias Biológicas. Unidad Profesional Adolfo \\ López Mateos. Av. Wilfrido Massieu S/N esq. Manuel L. Stampa, Nueva Industrial Vallejo, Gustavo \\ A. Madero, C.P. 07738, Ciudad de México, México.
}

\begin{abstract}
BACKGROUND

Three yeast strains with probiotic potential, Hanseniaspora opuntiae, Pichia kudriavzevii, and Wickerhamomyces anomalus were inoculated in the fermentation of Guajillo chilli pepper (Capsicum annuum L.) sauce, and the different aroma profiles were investigated. Using headspace solid phase microextraction-gas chromatography-mass spectrometry (HS-SPME-GC-MS) analysis and gas chromatography-olfactometry (GCO), flavour compounds production was evaluated during the fermentation of the Guajillo chilli pepper sauces.
\end{abstract}

RESULTS

A total of 78 volatile compounds were identified during the yeast fermentation of the sauce. Most aldehydes and terpenes detected were present since the beginning of the fermentation, indicating a Guajillo chilli pepper origin. Among the 34 active aroma compounds detected by GCO, propanoic acid (cheesy), 3-methylbutanoic acid (sharp, cheese), ethyl 2-methylbutanoate (fruity), and 6-methyl5-hepten-2-one (strong, citrus) were identified as key aroma contributors produced by the inoculation of the yeasts. Different aroma profile was produced by probiotic yeast. $H$. opuntiae produced an

This article has been accepted for publication and undergone full peer review but has not been through the copyediting, typesetting, pagination and proofreading process which may lead to differences between this version and the Version of Record. Please cite this article as doi: $10.1002 /$ jsfa. 10556 
aroma profile with herbal and green notes based on high production of aldehydes, ketones, and acetic acid. $P$. kudriavzevii and $W$. anomalus produced fruity, green-herbal, and cheesy notes based on ester compounds, alcohol and branched-chain acids production although, the production of propanoic acid by $W$. anomalus increased the cheesy character in the sauces.

\section{CONCLUSION}

The aroma profile of fermented chilli pepper sauces depends not only on the chili pepper varieties used but also on the fermentation process as a source of aroma compounds. The use of probiotic yeast can be used to improve and diversify the aroma profile of fermented chilli pepper sauces.

Keywords: Chili pepper; aroma; yeast; Hanseniaspora opuntiae; Pichia kudriavzevii; Wickerhamomyces anomalus. 


\section{INTRODUCTION}

Chilli peppers are used in the Mexican daily diet. Within the Capsicum genus, the Capsicum annuum L. specie is the most widely consumed in fresh or processed food, in sauces, powder, and pickled. ${ }^{1}$ Among sauces, the "borracha sauce", elaborated with Guajillo chilli peppers, a variety of $C$. annuum L., is characterised by its alcoholic content produced during a spontaneous fermentation. ${ }^{2}$ Nowadays, the fermentation of vegetables with autochthonous starters is a method that maintains or improves the nutritional value, sensory properties, and increased shelf life. ${ }^{3}$ Aroma is one of the most important indicators to determine the quality of fermented foods and consumers acceptance, and is based on the production of volatile compounds with aroma properties. ${ }^{4}$ There are several studies about the aroma profile of Capsicum fruits, and its changes according to the variety, ripening stages, and storage method. ${ }^{5}$ The most abundant compounds reported are esters, alcohols, aldehydes, ketones, terpenes, acids, furans, pyrazines, and sulphur compounds, which are responsible for the aroma characteristics. ${ }^{5-7}$ The production of volatile compounds in the spontaneous fermentation of red hot chilli peppers by lactic acid bacteria and yeasts affected the characteristic product flavour. ${ }^{8}$ Moreover, the fermentation of tomato and red pepper pomaces by Kluyveromyces marxianus and Debaryomyces hansenii resulted in different aroma notes produced by acids, esters, and alcohols. ${ }^{9}$ Therefore, not only chilli pepper varieties may affect the aroma profile but also the fermentation process may be provide a different source for aroma compounds. ${ }^{7,10}$ Still, few studies have focused on the effect of yeast inoculation on aroma fermentation.

Among the beneficial microorganisms known as probiotics in fermented vegetables, many yeasts have been isolated from vegetables. ${ }^{11}$ However, the use of probiotics in fermented foods can produce an impact on sensory properties..$^{12}$ There is still a limitation of probiotic yeasts contribution to aroma compounds production. In spontaneous fermented Guajillo pepper, three yeast strains, Hanseniaspora opuntiae, Pichia kudriavzevii, and Wickerhamomyces anomalus, with different probiotic characteristics were isolated. ${ }^{13}$ The antioxidant activity of these yeasts inoculated in Guajillo chilli pepper fermentations could impart a positive effect on Guajillo sauces' chemical composition during and after product manufacturing. However, the role of these probiotic yeast strains in the 
fermentation of Guajillo sauce is not known and it can affect the aroma profile and sauce quality. Therefore, the aim of this study was to investigate the different aroma profile produced by the inoculation of yeast strains with probiotic potential, H. opuntiae, P. kudriavzevii and W. anomalus, on the fermentation of Guajillo chilli pepper sauce.

\section{MATERIALS AND METHODS}

\section{Yeast strains and preparation of yeast suspensions}

Three yeast strains, Hanseniaspora opuntiae IPNFG2, Pichia kudriavzevii IPNFG5 and Wickerhamomyces anomalus IPNFG3 previously isolated during the fermentation process of Guajillo chilli peppers ${ }^{13}$ were used in this study. Yeast strains were maintained on GPYA medium $(20 \mathrm{~g} / \mathrm{L}$ glucose, $5 \mathrm{~g} \mathrm{~L}^{-1}$ peptone, $5 \mathrm{~g} \mathrm{~L}^{-1}$ yeast extract, and $20 \mathrm{~g} \mathrm{~L}^{-1}$ agar; $\mathrm{pH}$ 6.5). Fresh cells were collected by centrifugation at $4000 \mathrm{rpm}$ at $10 \mathrm{~min}$ from GPYA medium and suspended in physiological saline solution. Yeast suspensions at OD $655 \mathrm{~nm}$ (Biophotometer AG Eppendorf 22331, Hamburg, Germany) were prepared and adjusted to reach a final concentration of $10^{6}$ cells $\mathrm{mL}^{-1}$ in Guajillo sauce (GS).

\section{Fermentation conditions for production of Guajillo pepper sauce}

Guajillo chilli peppers (C. annuum L.) were washed with sterile, distilled water and sliced in hygienic conditions. A brine solution was prepared with $75 \mathrm{~g} \mathrm{~L}^{-1}$ glucose and $15 \mathrm{~g} \mathrm{~L}^{-1}$ sodium chloride and sterilised in an autoclave at $121{ }^{\circ} \mathrm{C}$ for $20 \mathrm{~min}$. Guajillo sauce was prepared mixing the brine solution and sliced Guajillo chilli peppers (300 $\left.\mathrm{g} \mathrm{L}^{-1}\right)$ in a blender until fully homogenised. Flasks of $250 \mathrm{~mL}$ containing $80 \mathrm{~mL}$ of GS were inoculated with the yeast strains ( $10^{6} \mathrm{CFU}$ per $\mathrm{ml}$ in each flask) and a non-inoculated flask was used as control. A total of five batches were obtained: C (control noninoculated), Ho ( $H$. opuntiae), Pk (P. kudriavzevii), Wa (W. anomalus), and T (inoculated with a mix of the three yeasts in the same proportion). Incubation of Guajillo sauce fermentation flasks was at $30{ }^{\circ} \mathrm{C}$ for 4 days without agitation. Each experiment was conducted in triplicate. During incubation, yeast count and volatile analyses of samples from each batch took place at $0,1,2,3$ and 4 days, 
with olfactometry aroma analysis at the end of the fermentation (4 d) in the $\mathrm{T}$ batch. $\mathrm{pH}$ was measured at the beginning and the end of the fermentation with a pH metre HI 99163 (Hanna Instruments Inc., Hoonsocket, USA).

\section{Yeast counts}

Yeast counts were done on $25 \mathrm{~g}$ of GS. Samples were mixed with $225 \mathrm{~mL}$ of buffered peptone water and homogenised in a Pulsifier (Microgen Biotech, Spain). Homogenates were used to prepare decimal dilutions which were spread on Rose Bengal Agar with chloramphenicol (100 g L $\mathrm{L}^{-1}$ dextrose, $50 \mathrm{~g} \mathrm{~L}^{-1}$ bacteriological peptone, $10 \mathrm{~g} \mathrm{~L}^{-1}$ potassium phosphate, $5 \mathrm{~g} \mathrm{~L}^{-1}$ magnesium sulphate, $1 \mathrm{~g} \mathrm{~L}^{-1}$ chloramphenicol, $0.5 \mathrm{~g} \mathrm{~L}^{-1}$ rose Bengal, $15 \mathrm{~g} \mathrm{~L}^{-1}$ bacteriological agar) and incubated at $30{ }^{\circ} \mathrm{C}$ for 48 h.

\section{Profile and Quantification of Volatile Compounds}

An Agilent HP 7890 series II GC (Hewlett-Packard, Palo Alto, CA, USA) with an HP 5975C mass selective detector (Hewlett-Packard) equipped with Gerstel MPS2 multipurpose sampler (Gersterl, Mülheim an der Ruhr, Germany) was used in all experiments. Extraction of headspace (HS) volatile compounds were performed using solid phase microextraction (SPME) with an $85 \mu \mathrm{m}$ Carboxen ${ }^{\circledR} /$ Polydimethylsiloxane (CAR/PDMS) fibre (Supelco, Bellefonte, PA, USA). For each experiment $3 \mathrm{~g}$ of $\mathrm{GS}$ and $1 \mathrm{~g}$ of sodium chloride were weighed into a $20 \mathrm{~mL}$ vial sealed with a PTFE faced silicone septum and analysed. The vial was maintained at $50^{\circ} \mathrm{C}$ for 15 min to equilibrate the headspace, and the fibre was exposed to the HS for $10 \mathrm{~min}$ at the same temperature. Previously, volatile extraction conditions were assayed at different extraction times $(5,10,20$, and $30 \mathrm{~min})$ to select the appropriate one. The compounds adsorbed by the fibre were desorbed in the gas chromatograph injection port for $5 \mathrm{~min}$ at $240^{\circ} \mathrm{C}$ in splitless mode. The compounds were separated

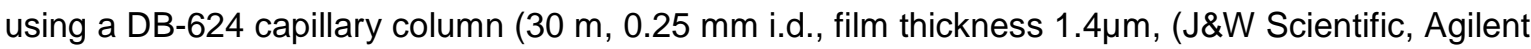
Technologies, Santa Clara, CA, USA)). Helium was used as the carrier gas with a linear velocity of $34.337 \mathrm{~cm} / \mathrm{s}$. The $\mathrm{GC}$ oven temperature programme began at time 0 min and $40{ }^{\circ} \mathrm{C}$, ramped to 140 
${ }^{\circ} \mathrm{C}$ at $3{ }^{\circ} \mathrm{C} / \mathrm{min}$, then $4{ }^{\circ} \mathrm{C} / \mathrm{min}$ to $220^{\circ} \mathrm{C}$ and maintained for $5 \mathrm{~min}$. The total run time was $58.33 \mathrm{~min}$. Mass spectra were obtained by electron impact at $70 \mathrm{ev}$, and data were acquired across the range $29-400$ amu.

Compounds were identified by comparison with mass spectra from the library database (Nist' 05), Linear Retention Index (LRI) ${ }^{14}$ and by comparison with authentic standards. Identified volatile compounds were quantified in SCAN mode using either a total or extracted ion chromatogram (TIC or EIC) on an arbitrary scale. Abundance of volatile compounds is expressed in TIC $\times 10^{5}$. Each GS batch was analysed per duplicate.

\section{Analysis of aroma compounds by Gas chromatography-olfactometry (GCO).}

A gas chromatograph with flame ionization detector (GC-FID) (Agilent 6890, Santa Clara, CA, USA) equipped with a sniffing port (ODP3, Gerstel, Mülheim an der Ruhr, Germany) was used to analyse aroma compounds as described by Corral et al. ${ }^{15}$ For aroma extraction, $2 \mathrm{~g}$ of GS and $0.66 \mathrm{~g}$ of sodium chloride were added to a $10 \mathrm{~mL} \mathrm{HS}$ vial, and equilibrated at $50{ }^{\circ} \mathrm{C}$ for $30 \mathrm{~min}$ in a thermo block (J.P. Selecta, Barcelona, Spain) and the same SPME fibre (CAR/PDMS) as above was used and exposed to the $\mathrm{HS}$ for $1 \mathrm{~h}$ at $50^{\circ} \mathrm{C}$. The highest extraction time was used to help identify and describe the aroma compounds by the panellists. Fibre was desorbed in the injection port for 15 min at $240^{\circ} \mathrm{C}$ in splitless mode. Then compounds were separated using a DB-624 capillary column (60 m, $0.32 \mathrm{~mm}$ i.d., film thickness $1.8 \mu \mathrm{m}$, (J\&W Scientific, Agilent Technologies, Santa Clara, CA, USA)). Helium was used as the carrier gas at a flow rate of $47 \mathrm{~cm} / \mathrm{s}$. The oven temperature program began at $40{ }^{\circ} \mathrm{C}$ for $5 \mathrm{~min}$, ramped to $140{ }^{\circ} \mathrm{C}$ at $3{ }^{\circ} \mathrm{C} / \mathrm{min}$, then ramped to $210{ }^{\circ} \mathrm{C}$ at $4{ }^{\circ} \mathrm{C} / \mathrm{min}$ and maintained for $5 \mathrm{~min}$, the total run time was $60.83 \mathrm{~min}$ and the detector temperature was set at 240 ${ }^{\circ} \mathrm{C}$. The sniffing port ODP3 equipped with a humidified air make up and a computer voice recorder interacted in the ChemStation software (Agilent, USA). The detection frequency method was used to estimate the aroma impact of each volatile compound. ${ }^{16}$ Four trained assessors evaluated the odour from the GC-effluent. A total of 9 assessments were conducted on the inoculated $T$ batch of GS. The final detection frequency value (DF) for each compound was obtained by summation of the 
9 "sniffings". The detection of an odour by less than two assessors was considered noise. For each assessment, evaluation of the odour took place over two different time intervals of $30 \mathrm{~min}$. Aroma compounds were identified by three different methods: comparison with mass spectra and Liner Retention Indices obtained for the same samples in the GC-MS, comparison with the Linear Retention Indices of authentic standards, and by coincidence of the assessors' descriptors with those in the Fenaroli's handbook of flavour ingredients. ${ }^{17}$

\section{Statistical analysis}

Data were analysed using generalised linear model (GML) procedure of statistical software XLSTAT 2018 (Addinsoft, Paris, France). The model includes the effect of yeast inoculation and time of fermentation as a fixed effect and replicates as random effects. When significant effect of the treatment group was detected $(P<0.05)$, least square means $(\mathrm{LSM})$ were compared using Tukey test. At the end of the fermentation (4 d), principal component analysis (PCA) and a heat map were done. PCA evaluated the relationships among different inoculated yeasts and all volatile compounds produced, while the heatmap was calculated based on the relative concentration of identified odouractive compounds produced by yeast strains.

\section{RESULTS AND DISCUSSION}

\section{Yeast growth on Guajillo sauce fermentation}

Yeast growth increased up to $2-3 \times 10^{8} \mathrm{CFU} \mathrm{mL} \mathrm{L}^{-1}$ after $1 \mathrm{~d}$ of fermentation (Fig. 1) except for Ho fermentation, which reached its maximum growth at $2 \mathrm{~d}$. Yeast growth was similar in $\mathrm{Pk}, \mathrm{Wa}$, and $\mathrm{T}$ fermentations, whereas Ho population decreased after $3 \mathrm{~d}$ of fermentation. No yeasts were found in the control (non-inoculated) batch sauce (C). The high yeast counts reached at the end of GS fermentation by $\mathrm{Pk}$ and Wa yeasts are comparable with the standards for commercially available probiotic formulations. ${ }^{18}$

The Sauces' pH was $5.31 \pm 0.16$ at the initial fermentation time and decreased in all batch sauces at the end of fermentation. Control and Ho sauces reached the lowest $\mathrm{pH}$ at $3.9 \pm 0.1$ and $3.8 \pm 0.2$ 
respectively, while $\mathrm{Pk}, \mathrm{Wa}$, and $\mathrm{T}$ sauces were always above $\mathrm{pH} 4(4.6 \pm 0.1,4.6 \pm 0.2$, and $4.4 \pm$ 0.1 , respectively). Decrease of $\mathrm{pH}$ occurs commonly during vegetable fermentation and has been reported during the acidification of red and yellow peppers by lactic acid bacteria. ${ }^{19}$ The presence of lactic acid bacteria was evaluated on MRS media, but no growth was detected (data not shown). In comparison, our results show a final pH consistent with the lowest acidification power of yeast versus lactic acid bacteria. ${ }^{20}$ Moreover, $H$. opuntiae population decreased significantly after $3 \mathrm{~d}$ (Fig. 1), due to acid accumulation and decrease of $\mathrm{pH}$ in the GS.

\section{Evolution of volatile compounds during fermentation}

Table 1 shows the identification of volatile compounds by GC-MS in the control and fermented GS. A total of 78 volatile compounds were found, including aldehydes (10), alcohols (15), sulphides (2), acids (7), esters (19), ketones (5), nitrogen compounds (2), furans (3), terpenes (13), and miscellaneous compounds (2). Among them 18 were tentatively identified by mass spectrum (Table 1). Forty-six volatile compounds were detected at the beginning of the fermentation, therefore, they must be naturally present in the Guajillo chilli peppers. Most of them have been reported previously in different fresh varieties of chilli peppers..$^{6,7,21}$

The production of volatile compounds in each GS depended on fermentation time and inoculated yeast as shown in Table S1 (supplementary material). While, the evaluation of the ability of the yeasts to generate volatile compounds at the end of the fermentation (4 d) was done by PCA analysis (Fig. $2(A, B)$ ). A projection of variables (grouped by chemical group) obtained for the four yeast batches explained $81.99 \%$ of the total variance. Principal component 1 (PC1) accounted for $65.5 \%$ of the variability and distinguishes GS by fermenting yeast. Sauce Ho appears in the left quadrant, Wa and $\mathrm{T}$ are in the centre and Pk appears in the right quadrant. In contrast, Principal component 2 (PC2) explained $16.5 \%$ of the variability and was because of the experimental replicates. It is worth noting that sauce Ho seems to be different from the other sauces, as all replicates are in the negative part of the $x$ axis in Fig. 2A. The most relevant characteristic of Ho sauce seems to be the high abundance 
of acetic acid ( 3 to 5 times more than the other sauces, Table S1), which would contribute to the decrease of $H$. opuntiae population at the end of the fermentation.

Thirty-eight active aroma zones were identified in fermented GS by mass spectra, linear retention indices, and odour description, although 4 of them were not identified (Table 2). The highest detection frequency (DF) values mean the highest aroma impact. The most potent odorants detected were propanoic acid (cheesy), 3-methylbutanoic acid (sharp, cheese), ethyl 2-methylbutanoate (fruity, fresh, banana, strawberry), 6-methyl-5-hepten-2-one (strong, citrus, green), benzaldehyde (strange mushrooms), 3-methylbutyl propanoate (sweet, fruity, fresh, strawberry), ethyl octanoate (sweet, green, herbaceous), and 2-acetylpyrrole (musty, sweet, vegetable). The effect of incubation time was significant in all aroma compounds seen in Fig. 3 and Table S1.

To show the aroma profile of odour-active compounds generated by each yeast strain, a heatmap with hierarchical clustering was represented (Fig. 4). The dendrogram at the top shows that the four yeast fermentations divided into two groups, one including all replicates of Ho-t4 and the second group all replicates of Pk-t4, Wa-t4, and T-t4. This second group is further divided in two groups, differentiating Pk-t4 and Wa-t4 from $\mathrm{T}-\mathrm{t} 4$. The heatmap shows the relative lowest production of aroma ester compounds and alcohols by Ho-t4 batches, except for ethyl 2-methylbutanoate. Moreover, Hot4 batches showed the highest relative production of 6-methyl-3,5-heptadiene-2-one and 2,2,6trimethyl cyclohexanone.

Acids described as potent aroma contributors, such as 2-methylpropanoic and 3-methylbutanoic acids were produced in Wa-t4 batches, while propanoic acid appeared in Wa and T batches. This confirms that vegetable fermentations produced by these yeasts differ from other characteristic foods. This is like traditional pickled peppers fermented by lactic acid bacteria, were acetic acid is an aroma contributor. ${ }^{22}$ but not in GS sauces (Table 2), although it was produced in Ho sauces. In other pepper fermentations, like Korean fermented chilli pepper paste (Gochujang) fermented by Lactobacillus parabuchneri, several ester compounds (ethyl 2-methylpropanoate and ethyl butyrate, among others) were reported as aroma contributors. ${ }^{23}$ Mixed fermentations of red hot chilli pepper mash, by Lactobacillus lactis and Saccharomyces cerevisiae, produced the intensification of volatile 
compounds such as alcohols and esters. ${ }^{8}$ Still, this fermentation is different from the GS, which are characterised by the low production of aldehydes (Fig. 3a).

Our study shows the highest abundance of aromatic esters in Pk, Wa, and T sauces (Fig. 3d). Among the aromatic esters, the most potent compounds were branched-chain esters and medium-chain fatty acid (MCFA) ethyl esters contributing with fruity and sweet notes (Table 2). Among all the alcohols identified in the fermented sauces (Table 1), five of them (2-methyl-1-butanol, 3-methyl-2-buten-1ol, 3-ethoxy-1-propanol, 6-methyl-5-hepten-2-ol and benzylalcohol) have not been reported in the fermentation of chilli peppers before. ${ }^{8,21-23}$ Moreover, 6-methyl-5-hepten-2-ol and benzylalcohol have been detected as odour-active compounds in our study, although benzylalcohol does not appear to be produced by the inoculated yeasts, since the highest abundance was found in the non-inoculated batch (Table S1).

Regarding aldehydes, Ho sauce contained the highest abundance followed by $\mathrm{C}, \mathrm{Pk}, \mathrm{Wa}$, and $\mathrm{T}$ sauces (Table S1). Lara-Hidalgo et al. ${ }^{13}$ reported the lower oxidant power of $H$. opuntiae compared to the other two yeast strains. Therefore, it might be possible that other microorganisms in the control sauce prevented the oxidation of alcohols for the formation of aldehydes. Among aromatic aldehydes (Fig. 3a), benzaldehyde and 3-methylbutanal have been reported as components in the aroma profile of fermented pickled peppers ${ }^{22}$ and Gochujang. ${ }^{23}$ These compounds usually contribute to herby and malty flavours, respectively; however, in this study descriptors as strange mushrooms and fruity were reported for these compounds and other aldehydes contributed the green and herbal notes (Table 2). The corresponding alcohols or acids derived from 3-methylbutanal (3-methyl-1-butanol/3-methyl butanoic acid), hexanal (hexanol/hexanoic acid), and benzene acetaldehyde (phenylethyl alcohol) were too detected (Table 1).

The ketones identified in our study (Table 1) have already been reported previously in $C$. annuum fresh fruits. ${ }^{7,24}$ In our study, the abundance of 6-methyl-5-hepten-2-one increased significantly at 24 h of fermentation, most probably due to $P$. kudriavzevii and $W$. anomalus inoculation and decreased until the third day of fermentation, increasing again later (Table S1). Mo et al. ${ }^{25}$ have described these compounds as intermediates for the production of other volatile compounds. Yan et al. ${ }^{26}$ detected an 
increment of ketones in the fermentation of Daqu, a Chinese liquor produced from cereals, carried out by non-Saccharomyces, of which yeasts $P$. kudriavzevii and $W$. anomalus where among them. The presence of furans and nitrogen compounds identified in GS (Table 1) has been reported in fresh ripened C. annuum, paprika, and Gochujang, ${ }^{6,26,27}$ but their contribution to the aroma has not been explained. Our results show a contribution of these compounds to toasted and sweet notes, which are associated to Maillard reactions. ${ }^{28}$

Terpene production increased irregularly during GS fermentation (Fig. 3h and Table S1). These changes could be attributed to yeast or microbial metabolism that could break the terpene-sugar bond and enhance terpene release, and subsequent bioconversions in other terpenes or aromatic compounds. ${ }^{29}$ These volatiles contributed to fresh, green, and spice aroma notes (Table 2), and have not been reported before as aroma contributors in this variety of chilli pepper. ${ }^{23}$

In summary, this is the first time that the contribution of potential probiotic yeasts to the aroma profile of Guajillo pepper (Capsicum annuum L.) sauce has been described. The use of different yeast in GS fermentation provided different aroma notes and profiles. P. kudriavzevii and W. anomalus produced a similar aroma profile in GS with fruity, green-herbal, and cheesy odour notes based on ester compounds, alcohol, and branched-chain acids production. However, W. anomalus inoculation increased the cheesy character in GS because of its ability to produce propanoic acid. In contrast, inoculation of $H$. opuntiae produced a completely different aroma profile in GS with herbal and green notes based on high production of aldehydes, ketones, and acetic acid but with low fruity character. Moreover, the contribution of $H$. opuntiae inoculation in the T sauce aroma seems to be insignificant. The use of yeast mixtures ( $T$ ) affected positively the aroma of GS sauces with the production of key aroma compounds. Among these, propanoic acid (cheesy), 3-methylbutanoic acid (sharp, cheese), ethyl 2-methylbutanoate (fruity), and 6-methyl-5-hepten-2-one (strong, citrus), in conjunction with additional 31 compounds, rounded off the aroma of the fermented sauce. In conclusion, these results provide a new perspective for improvement and diversification of the aroma quality of fermented traditional foods and establish a basis for further research on the properties of Guajillo sauce such as processing conditions, stability, consumer acceptance, and purchase intention. 


\section{ACKNOWLEDGEMENTS}

Lara-Hidalgo and Dorantes-Alvarez thanks CONACyT, COFFAA-IPN and SIP20195428 of IPN for the fellowship granted to conduct the research stay. Also, the financial support from RTI2018098074-B-I00 (MCIU/AEI/FEDER, UE) is fully acknowledged.

\section{REFERENCES}

1 Laborde J and Pozo O, Presente y pasado del chile en México. México, DF: Secretaría de Agricultura y Recursos Hidraúlicos; (1982).

2 Vera-Guzmán AM, Aquino-Bolaños EN, Heredia-García E, Carrillo-Rodríguez JC, Hernández-Delgado S and Chávez-Servia JL, Flavonoid and capsaicinoid contents and consumption of mexican chili pepper (Capsicum annuum L.) landraces. In: Goncalo C. Justino, ed. Flavonoids - From Biosynthesis to Human Health Rijeka, Croatia: INTECH; p. 405-437, (2017).

3 Cagno R Di, Cardinali G, Minervini G, Antonielli L, Rizzello CG, Ricciuti P et al., Taxonomic structure of the yeasts and lactic acid bacteria microbiota of pineapple (Ananas comosus $\mathrm{L}$. Merr.) and use of autochthonous starters for minimally processing. Food Microbiol 27:381389 (2010).

4 Olivares A, Navarro JL and Flores M, Effect of fat content on aroma generation during processing of dry fermented sausages. Meat Sci 87:264-273 (2011).

5 Forero MD, Quijano CE and Pino JA, Volatile compounds of chile pepper (Capsicum annuum L. var. glabriusculum) at two ripening stages. Flavour Fragr J 24:25-30 (2009). Korkmaz A, Hayaloglu AA and Atasoy AF, Evaluation of the volatile compounds of fresh ripened Capsicum annuum and its spice pepper (dried red pepper flakes and isot). LWT Food Sci Technol 84:842-850 (2017).

$7 \quad$ Ziino M, Condurso C, Romeo V, Tripodi G and Verzera A, Volatile compounds and capsaicinoid content of fresh hot peppers (Capsicum annuum L.) of different Calabrian varieties. J Sci Food Agric 89:774-780 (2009).

8 Watts EG, Janes ME, Prinyawiwatkul W, Shen Yixiao, Xu Z and Johnson D, Microbiological changes and their impact on quality characteristics of red hot chilli pepper mash during natural fermentation. Int J Food Sci Technol 53:1816-1823 (2018).

9 Güneşer O, Demirkol A, Karagül Yüceer Y, Özmen Toğay S, İşleten Hoşoğlu M and Elibol $\mathrm{M}$, Bioflavour production from tomato and pepper pomaces by Kluyveromyces marxianus 
and Debaryomyces hansenii. Bioprocess Biosyst Eng 38:1143-1155 (2015).

Luning PA, Rijk T de, Wichers HJ and Roozen JP, Gas chromatography, mass spectrometry, and sniffing port analyses of volatile compounds of fresh bell peppers (Capsicum annuum) at different ripening stages. J Agric Food Chem 42:977-983 (1994).

11 Lara-Hidalgo C, Hernández-Sánchez H, Hernández-Rodríguez C and Dorantes-Álvarez L, Yeasts in fermented foods and their probiotic potential. Austin J Nutr Metab 4:1045-1 (2017).

Rivera-Espinoza $\mathrm{Y}$ and Gallardo-Navarro $\mathrm{Y}$, Non-dairy probiotic products. Food Microbiol 27:1-11 (2010). Lara-Hidalgo C, Dorantes-Alvarez L, Hernández-Sánchez H, Santoyo-Tepole F, MartínezTorres A, Villa-Tanaca $L$ et al., Isolation of yeasts from guajillo pepper (Capsicum annuum L.) fermentation and study of some probiotic characteristics. Probiotics Antimicro Prot 11:748-764 (2019). Dool $\mathrm{H}$ Van den and Kratz DP, A generalization of the retention index system including linear temperature programmed gas_liquid partition chromatography. J Chromatogr 2:463-471 (1963).

Corral S, Salvador A and Flores M, Salt reduction in slow fermented sausages affects the generation of aroma active compounds. Meat Sci 93:776-785 (2013).

Pollien P, Baumgartner M, Montigon F, Chaintreau A, Ott A, and Muñoz-Box R, Hyphenated headspace-gas chromatography-sniffing technique: screening of impact odorants and quantitative aromagram comparisons. J Agric Food Chem 45:2630-2637 (2002). Burdock GA. Fenaroli's handbook offlavor ingredients. Boca Raton, Florida: CRC Press Inc; (2002).

Boyle RJ, Robins-Browne RM and Tang MLK, Probiotic use in clinical practice: what are the risks? Am J Clin Nutr 83:1256-1264; quiz 1446-1447 (2006). Cagno R Di, Surico RF, Minervini G, Angelis M De, Rizzello CG and Gobbetti M, Use of autochthonous starters to ferment red and yellow peppers (Capsicum annum L.) to be stored at room temperature. Int J Food Microbiol 130:108-116 (2009). Martínez-Torres A, Gutiérrez-Ambrocio S, Heredia-del-Orbe P, Villa-Tanaca L and Hernández-Rodríguez $\mathrm{C}$, Inferring the role of microorganisms in water kefir fermentations. Int J Food Sci Technol 52:1-13 (2016).

21 Lee SM, Lee JY, Cho YJ, Kim MS and Kim YS, Determination of volatiles and carotenoid degradation compounds in red pepper fermented by Lactobacillus parabuchneri. J Food Sci 83:2083-2091 (2018). 
components in Chinese traditional pickled peppers using HS-SPME-GC-MS, GC-O and multivariate analysis. Nat Prod Res 24:1939-1953 (2010).

Kyung-Mo K and Baek $\mathrm{HH}$, Aroma quality assessment of Korean fermented red pepper paste (gochujang) by aroma extract dilution analysis and headspace solid-phase microextraction-gas chromatography-olfactometry. Food Chem 145:488-495 (2014).

24 Martín A, Hernández A, Aranda E, Casquete R, Velázquez R, Bartolomé T et al., Impact of volatile composition on the sensorial attributes of dried paprikas. Food Res Int 100:691-697 (2017).

25 Mo X, Fan W and Xu Y, Changes in volatile compounds of Chinese rice wine wheat Qu during fermentation and storage. J Inst Brew 115:300-307 (2009).

26 Yan S, Tong Q and Guang J, Yeast dynamics and changes in volatile compounds during the fermentation of the traditional Chinese strong-flavor Daqu. LWT - Food Sci Technol 106:57-63 (2019).

27 Baek $\mathrm{HH}$, Aroma quality assessment of Korean fermented red pepper paste (gochujang) by aroma extract dilution analysis and headspace solid-phase microextraction-gas chromatography-olfactometry. Food Chem 145:488-495 (2014).

28 Duan $\mathrm{H}$ and Barringer SA, Changes in furan and other volatile compounds in sliced carrot during air-drying. J Food Process Preserv 36:46-54 (2012).

29 Gamero A, Manzanares P, Querol A and Belloch C, Monoterpene alcohols release and bioconversion by Saccharomyces species and hybrids. Int J Food Microbiol 145:92-97 (2011). 


\section{FIGURE LEGENDS}

Figure 1. Yeast growth during the fermentation of Guajillo sauce (Control (₫); Ho, H. opuntiae ( $\bullet$ ); Pk, P. kudriavzevii ( $\diamond) ; W a, W$. anomalus $(\bullet) ; \mathrm{T}$, mixed culture (०).

Figure 2. Loadings of the first two principal components (PC1 - PC2) of Guajillo fermented sauce at the end of the fermentation ( $4 \mathrm{~d})(A)$, and volatile compounds produced (B). PCA shows the replicates of each yeast fermented sauce. Ho, H. opuntiae; Pk, P. kudriavzevii; Wa, W. anomalus; T, mixed culture.

Figure 3. Abundance of aroma compounds (Table 2), expressed as Total Ion Current, TIC per 105, produced during the fermentation of Guajillo sauce and classified according to chemical group. (a) aldehydes, (b) alcohols, (c) acids, (d) esters, (e) ketones, (f) nitrogen, (g) furans, and (h) terpenes compounds. Symbols represents the different batches; Control (घ), Ho, H. opuntiae (४); Pk, P. kudriavzevii ( $\diamond)$; Wa, W. anomalus (•); T, mixed culture (o).

Figure 4. Heatmap representing aroma profile including only odour-active compounds at $4 \mathrm{~d}$ of fermentation of GS (control C and yeast fermented: Ho, H. opuntiae; Pk, P. kudriavzevii; Wa, W. anomalus; T: mixed culture). The colours in the map represent the following: red colour indicates relatively high abundance; blue colour indicates relatively low abundance of each aroma compound; white colour indicates no difference. 
Table 1. Identicación of volatile compounds detected in the headspace of fermented Guajillo sauce with and without inoculated yeast strains

\begin{tabular}{|c|c|c|c|c|c|c|c|c|}
\hline \multirow[b]{2}{*}{ Compounds } & \multirow[b]{2}{*}{$\mathbf{L R I}^{2}$} & \multirow[b]{2}{*}{$\mathbf{R} \mathbf{l}^{3}$} & \multirow[b]{2}{*}{$\mathrm{C}^{4}$} & \multirow[b]{2}{*}{ C-t4 } & \multicolumn{4}{|c|}{ Yeasts } \\
\hline & & & & & Ho-t4 & Pk-t4 & Wa-t4 & T-t4 \\
\hline \multicolumn{9}{|l|}{ Aldehydes } \\
\hline Acetaldehyde & 460 & $\mathrm{a}$ & $+^{5}$ & + & + & + & + & + \\
\hline 2-Methylpropanal & 593 & $\mathrm{a}$ & + & - & - & - & - & - \\
\hline 3-Methylbutanal & 692 & a & + & + & - & - & - & - \\
\hline Diethyl acetal & 753 & a & - & + & + & + & + & + \\
\hline Hexanal & 844 & a & + & - & - & - & - & - \\
\hline Furfural & 899 & $\mathrm{a}$ & + & + & + & - & - & - \\
\hline Benzaldehyde & 1018 & a & + & + & + & + & + & + \\
\hline$(\mathrm{E}, \mathrm{E})-2,4$-Heptadienal & 1077 & a & + & - & - & - & - & - \\
\hline Benzene acetaldehyde & 1108 & a & + & + & + & + & + & + \\
\hline \multirow{2}{*}{\multicolumn{9}{|c|}{ Alcohols }} \\
\hline & & & & & & & & \\
\hline Ethanol & 509 & a & + & + & + & + & + & + \\
\hline 1-Propanol & 612 & a & - & + & + & + & + & + \\
\hline 2-Methyl-1-propanol & 679 & a & - & + & + & + & + & + \\
\hline 1-Butanol & 720 & b & - & + & - & + & + & + \\
\hline 3-Methyl-1-butanol & 790 & a & + & + & + & + & + & + \\
\hline 2-Methyl-1-butanol & 795 & a & - & + & + & + & + & + \\
\hline 3-Methyl-2-buten-1-ol & 829 & a & - & + & - & - & - & - \\
\hline 2,3-Butanediol [R-( $\left.\left.\mathrm{R}^{\star}, \mathrm{R}^{\star}\right)\right]-$ & 878 & a & + & + & + & + & + & + \\
\hline 2,3-Butanediol $\left[R-\left(R^{\star}, R^{\star}\right)\right]-$ & 886 & a & + & + & + & + & + & + \\
\hline 3-Ethoxy-1-propanol & 896 & a & - & - & + & + & + & + \\
\hline 1-Hexanol & 921 & a & - & + & + & + & + & + \\
\hline 6-Methyl-5-hepten-2-ol (95) & 1042 & a & - & + & + & + & + & + \\
\hline 2-Ethyl-1-hexanol & 1080 & a & + & + & + & + & + & + \\
\hline Benzylalcohol & 1121 & a & - & + & + & + & + & + \\
\hline Phenylethyl alcohol & 1196 & a & + & + & + & + & + & + \\
\hline \multicolumn{9}{|l|}{ Sulfide compounds } \\
\hline Dimethylsulfide (62) & 534 & a & + & - & - & - & - & - \\
\hline $\begin{array}{l}\text { 3-Methylthio-1-propanol } \\
\text { Acids }\end{array}$ & 1060 & a & - & - & + & - & + & + \\
\hline Acetic acid & 702 & a & + & + & + & + & + & + \\
\hline Propanoic acid & 793 & a & + & - & + & + & - & - \\
\hline 2-Methylpropanoic acid & 851 & a & + & + & + & + & + & + \\
\hline Butanoic acid & 881 & a & - & - & - & + & + & - \\
\hline 3-Methylbutanoic acid & 935 & a & + & + & + & + & + & + \\
\hline 2-Methylbutanoic acid & 941 & a & + & + & + & + & + & + \\
\hline Hexanoic acid & 1069 & a & + & - & + & + & + & + \\
\hline \multicolumn{9}{|l|}{ Esters } \\
\hline Ethyl formate & 540 & b & - & + & + & + & + & + \\
\hline Methyl acetate & 553 & a & - & + & + & + & + & + \\
\hline Ethyl acetate & 638 & a & + & + & + & + & + & + \\
\hline Ethyl propanoate & 739 & a & - & - & + & - & + & + \\
\hline Propyl acetate & 743 & a & - & - & + & + & + & + \\
\hline Ethyl 2-methylpropanoate & 783 & a & - & - & - & + & + & + \\
\hline 2-Methylpropyl acetate & 804 & a & - & - & + & + & + & + \\
\hline Ethyl butyrate & 827 & a & - & + & - & + & + & + \\
\hline Ethyl 2-Methylbutanoate & 875 & a & - & + & + & + & + & + \\
\hline
\end{tabular}


3-Methylbutyl acetate

2-Methylbutyl acetate

3-Methylbutyl propanoate

Ethyl hexanoate

Ethyl heptanoate

Ethyl octanoate

Methyl salicylate

2-Phenylethyl acetate

Ethyl nonanoate

Ethyl dodecanoate

\section{Ketones}

2,3-Butanedione

3-Hydroxy-2-butanone

6-Methyl-5-hepten-2-one

2,2,6-Trimethyl cyclohexanone

6-Methyl-3,5-heptadiene-2-one

Nitrogen compounds

Tetramethylpyrazine

2-Acetylpyrrole

Furans

2-Methylfuran

Acetylfuran (95)

2-Pentylfuran

Terpenes

D-Limonene (93)

a-Isophorone

4-Oxoisophorone

$\beta$-Cyclocitral

$\alpha$-Cubebene

$\beta$-Elemene

Longifolene

Terpene

Dihydropseudoionone

Longifolene

Eremophilane

Selinene

$\beta$-Ionone

Miscellaneous

p-Xylene

Safranal

$\begin{array}{rrrrrrrr}906 & \text { a } & - & + & + & + & + & + \\ 909 & \text { a } & - & - & + & + & + & + \\ 997 & \text { a } & - & - & - & + & + & + \\ 1026 & \text { a } & - & + & + & + & + & + \\ 1126 & \text { a } & - & - & + & + & + & + \\ 1226 & \text { a } & - & + & + & + & + & + \\ 1256 & \text { b } & - & - & - & + & + & - \\ 1315 & \text { a } & - & - & + & + & + & + \\ 1326 & \text { a } & - & - & + & + & + & + \\ 1626 & \text { b } & - & + & + & + & + & +\end{array}$

626 a $-\quad+\quad+\quad+\quad+$

779 a $-\quad+\quad+\quad+$

$1034 \mathrm{a}+\mathrm{t}+\mathrm{t} \quad+$

$1083 \mathrm{~b}+\quad+\quad-\quad+$

$1173 \mathrm{~b}+\mathrm{t} \quad+\quad+\quad+$

$\begin{array}{llllllll}1118 & \mathrm{a} & + & + & + & + & + & + \\ 1155 & \mathrm{a} & + & - & + & + & + & +\end{array}$

619 a + - -

$974 \mathrm{a}++\quad+\quad+\quad+$

$1011 \mathrm{a}+\mathrm{a}_{1}+\mathrm{C} \mathrm{+} \quad+$

$1044 \mathrm{a}+\mathrm{t} \quad+\quad+\quad+$

$1109 \mathrm{~b}+\mathrm{t}+\mathrm{t}+$

$1225 \mathrm{a}+\mathrm{a}+\mathrm{t} \quad-$

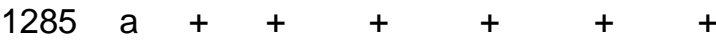

$1404 \mathrm{~b}+\mathrm{b}_{\mathrm{N}}+\mathrm{t} \quad+$

$1426 \mathrm{~b}+\mathrm{t} \quad+\quad+\quad+$

$1489 \mathrm{~b}+\mathrm{b}_{\mathrm{N}}+\mathrm{t}_{\mathrm{H}}+$

$1507 \mathrm{C}+\mathrm{C}_{1510}+\mathrm{C}_{+}+$

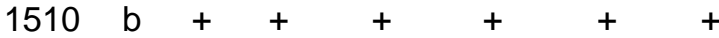

$1527 \mathrm{~b}+\mathrm{t} \quad+\quad+\quad+$

$1533 \mathrm{~b}+\mathrm{t} \quad+\quad+\quad+$

$1539 \mathrm{~b}+\mathrm{b}_{1567}+\mathrm{t} \quad+\quad+$

1567 a $+\quad+\quad+\quad+\quad+$

$894 \mathrm{a}+\quad+\quad+\quad+\quad+$

1264 b $+\quad+\quad+\quad+\quad+\quad+4 \quad+$

${ }^{1}$ Target ion used to quantify the compound when the peak was not completely resolved.

2 Linear retention indices (LRI) of the compounds eluted from the GC-MS using a DB-624 capillary column (J\&W Scientific $30 \mathrm{~m} \times 0.25 \mathrm{~mm}$ i.d. $\times 1.4 \mu \mathrm{m}$ film thickness).

${ }^{3}$ Reliability of identification: $\mathrm{a}$, identification by mass spectrum and by coincidence with the LRI of an authentic standard; $b$, tentative identification by mass spectrum; $c$ : unidentified compound.

${ }^{4} \mathrm{C}$ : Control batch without inoculated yeast and yeast inoculated batches at the end of the fermentation (4 d); Ho-t4, H. opuntiae; Pk-t4, P. kudriavzevii; Wa-t4, W. anomalus; T-t4, mixed culture.

${ }^{5}$ presence $(+)$ or absence (-) of compound in the headspace. 
Table 2. Odor active compounds identified in the headspace of Guajillo sauce at 4 days of fermentation

\begin{tabular}{|c|c|c|c|c|c|c|c|}
\hline & \multicolumn{2}{|c|}{ GC-MS $^{\mathbf{a}}$} & \multicolumn{2}{|c|}{$\mathbf{G C O}^{\mathbf{b}}$} & \multirow[b]{2}{*}{$\mathbf{R}^{\mathbf{c}}$} & \multirow[b]{2}{*}{ Descriptor } & \multirow[b]{2}{*}{ DF } \\
\hline Compound & LRI & $\begin{array}{l}\text { LRI } \\
\text { std }\end{array}$ & $\begin{array}{c}\text { LRI } \\
\text { Initial }\end{array}$ & $\begin{array}{l}\text { LRI } \\
\text { Final }\end{array}$ & & & \\
\hline \multicolumn{8}{|l|}{ Aldehydes } \\
\hline 3-Methylbutanal & 692 & 687 & 689 & 692 & $\mathrm{a}$ & Fruity & 3 \\
\hline Hexanal & 844 & 839 & 834 & 841 & $\mathrm{a}$ & Green, grassy & 3 \\
\hline Furfural & 899 & 898 & 901 & 904 & $\mathrm{a}$ & Sweet, fruity & 4 \\
\hline Benzaldehyde & 1018 & 1013 & 1017 & 1021 & $\mathrm{a}$ & Strange mushrooms & 8 \\
\hline$(\mathrm{E}, \mathrm{E})-2,4$-Heptadienal & 1077 & 1076 & 1075 & 1077 & $\mathrm{a}$ & Herbaceous, green & 3 \\
\hline Benzene acetaldehyde & 1108 & 1104 & 1108 & 1113 & $\mathrm{a}$ & Unpleasant, harsh & 5 \\
\hline 2,5-Dimethylbenzaldehyde & 1256 & 1257 & 1236 & 1252 & $\mathrm{a}$ & Spicy, brown odor & 7 \\
\hline \multicolumn{8}{|l|}{ Alcohols } \\
\hline 2-Methyl-1-propanol & 679 & 681 & 682 & 683 & $\mathrm{a}$ & Sweet, fruity & 3 \\
\hline 6-Methyl-5-hepten-2-ol & 1042 & 1040 & 1045 & 1049 & $\mathrm{a}$ & Green, fresh & 3 \\
\hline Benzyl alcohol & 1121 & 1120 & 1116 & 1119 & $\mathrm{a}$ & Green, herbal & 3 \\
\hline Phenylethyl alcohol & 1196 & 1191 & 1196 & 1205 & $\mathrm{a}$ & Chemical, camphor & 7 \\
\hline \multicolumn{8}{|l|}{ Acids } \\
\hline Propanoic acid & 793 & 806 & 784 & 787 & $\mathrm{a}$ & Cheesy & 9 \\
\hline 2-Methylpropanoic acid & 851 & 864 & 867 & 869 & $\mathrm{a}$ & Cheese, unpleasant & 4 \\
\hline 3-Methylbutanoic acid & 941 & 947 & 920 & 927 & $\mathrm{a}$ & Sharp, cheese & 9 \\
\hline \multicolumn{8}{|l|}{ Esters } \\
\hline Ethyl 2-methylpropanoate & 783 & 786 & 781 & 784 & $\mathrm{a}$ & Sweet, fruity, strawberry, banana & 5 \\
\hline Ethyl butyrate & 827 & 829 & 824 & 827 & a & Fruity, sweet, peach odor & 4 \\
\hline Ethyl 2-methylbutanoate & 875 & 876 & 871 & 873 & $\mathrm{a}$ & Fruity, fresh, banana, strawberry & 9 \\
\hline 3-Methylbutyl acetate & 906 & 905 & 906 & 910 & $\mathrm{a}$ & Sweet, citrus, green & 3 \\
\hline 3-Methylbutyl propanoate & 997 & 996 & 987 & 990 & $\mathrm{a}$ & Sweet, fruity, fresh, strawberry & 8 \\
\hline Ethyl hexanoate & 1026 & 1026 & 1021 & 1024 & $\mathrm{a}$ & Fruity, sweet & 6 \\
\hline Ethyl octanoate & 1226 & 1226 & 1221 & 1224 & a & Sweet, green, herbaceous & 8 \\
\hline Ethyl nonanoate & 1326 & 1327 & 1324 & 1327 & $\mathrm{a}$ & Alcohol, wine & 5 \\
\hline \multicolumn{8}{|l|}{ Ketones } \\
\hline 6-Methyl-5-hepten-2-one & 1034 & 1031 & 1028 & 1032 & $\mathrm{a}$ & Strong, citrus, green & 9 \\
\hline $2,2,6$-Trimethylcyclohexanone & 1083 & & 1087 & 1089 & $\mathrm{~b}$ & Sweet, caramel & 5 \\
\hline 6-Methyl-3,5-heptadiene-2-one & 1173 & & 1159 & 1165 & $\mathrm{~b}$ & Spicy, green & 5 \\
\hline \multicolumn{8}{|l|}{ Nitrogen compounds } \\
\hline $\begin{array}{l}\text { 2-Acetylpyrrole } \\
\text { Furans }\end{array}$ & \multicolumn{6}{|c|}{ Furans } & 8 \\
\hline Acetylfuran & 974 & 968 & 962 & 965 & $\mathrm{a}$ & Toasted, grilled & 4 \\
\hline 2-Pentylfuran & 1011 & 1009 & 1001 & 1006 & $\mathrm{a}$ & Sweet, fresh & 4 \\
\hline \multicolumn{8}{|l|}{ Terpenes } \\
\hline a-Isophorone & 1109 & & 1104 & 1110 & $\mathrm{~b}$ & Fruity, fermented & 4 \\
\hline 4-Oxoisophorone & 1225 & 1221 & 1205 & 1211 & $\mathrm{a}$ & Pepper, spicy, green, herbal & 7 \\
\hline$\beta$-Cyclocitral & 1285 & 1286 & 1281 & 1293 & $\mathrm{a}$ & Fresh, green, vegetable & 5 \\
\hline a-Cubebene & 1404 & & 1395 & 1402 & $b$ & Green, waxy & 4 \\
\hline$\beta$-Elemene & 1426 & & 1467 & 1477 & $\mathrm{~b}$ & Fresh, spicy & 7 \\
\hline Longifolene & 1489 & & 1471 & 1474 & $\mathrm{~b}$ & Sweet, fresh, herbaceous & 4 \\
\hline \multicolumn{8}{|l|}{ Others } \\
\hline Unknown & & & 707 & 714 & $\mathrm{c}$ & Sulphurous, unpleasant & 4 \\
\hline Unknown & & & 955 & 957 & $\mathrm{C}$ & Sweet, caramellic & 5 \\
\hline Unknown & & & 967 & 970 & $\mathrm{C}$ & Mushrooms, fermented vegetable & 6 \\
\hline Unknown & & & 1185 & 1189 & $\mathrm{C}$ & Herbaceous & 5 \\
\hline
\end{tabular}

aLinear retention indices (LRI) of the compounds eluted from the GC-MS and LRI of standard compound using a DB-624 capillary column (J\&W Scientific $30 \mathrm{~m} \times 0.25 \mathrm{~mm}$ i.d. $\times 1.4 \mu \mathrm{m}$ film thickness).

bInitial and end linear retention index (LRI) of the compounds eluted from the GC-FID-O using a DB-624 column capillary column (60 m x $0.32 \mathrm{~mm}$ i.d. $\times 1.8 \mu \mathrm{m}$ film thickness). 
${ }^{\mathrm{C}} \mathrm{RI}$ : reliability of identification: $\mathrm{a}$, identification by mass spectrum and by coincidence with the LRI of an authentic standard and by coincidence of the assessors' descriptors with those in the Fenaroli's handbook of flavour ingredients (Burdock, 2002), b, tentative identification by mass spectrum, c: not identified.

dDF: Detection frequency value. 


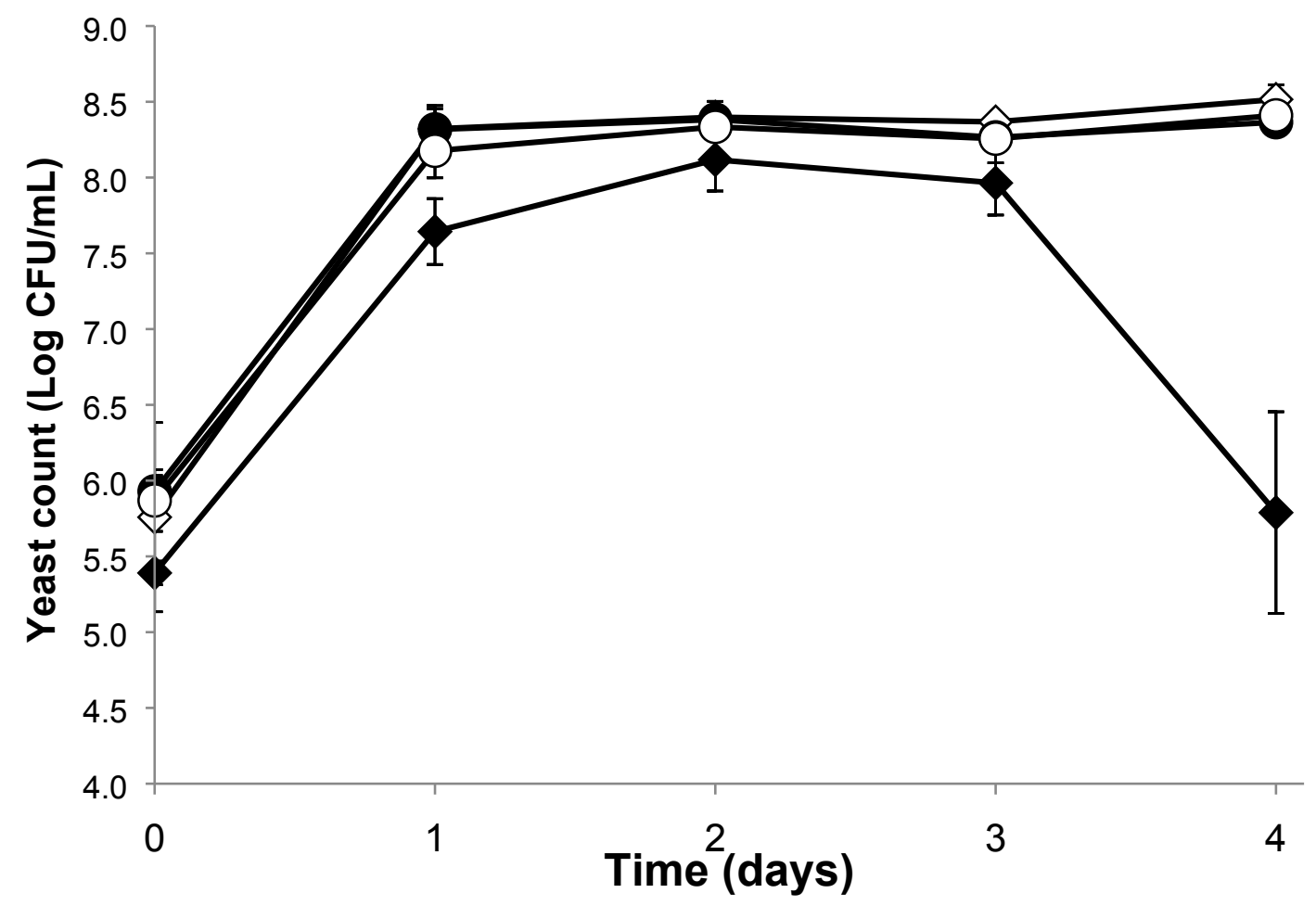

Figure 1. 

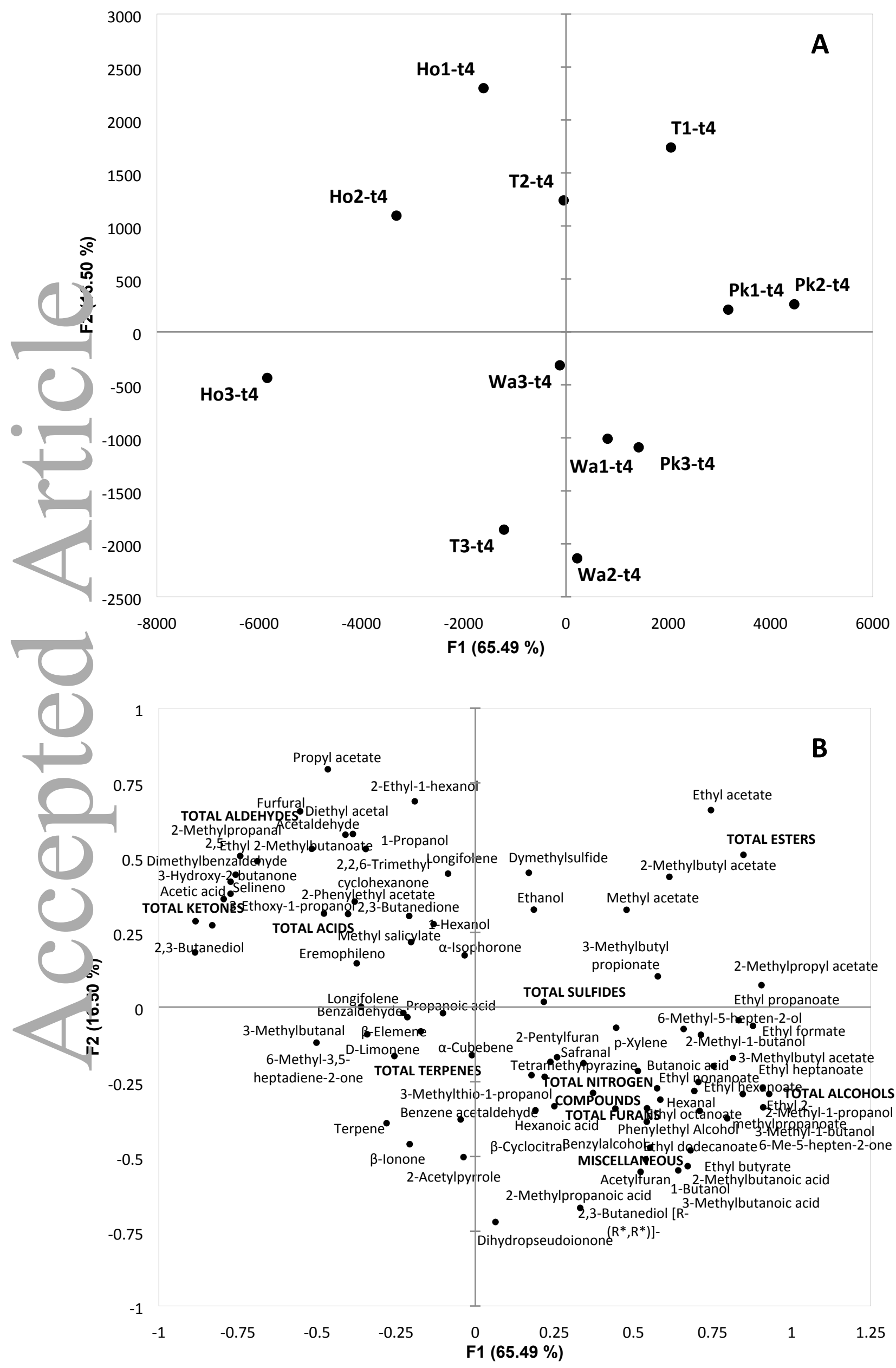

This article is protected by copileyright. All rights reserved. 

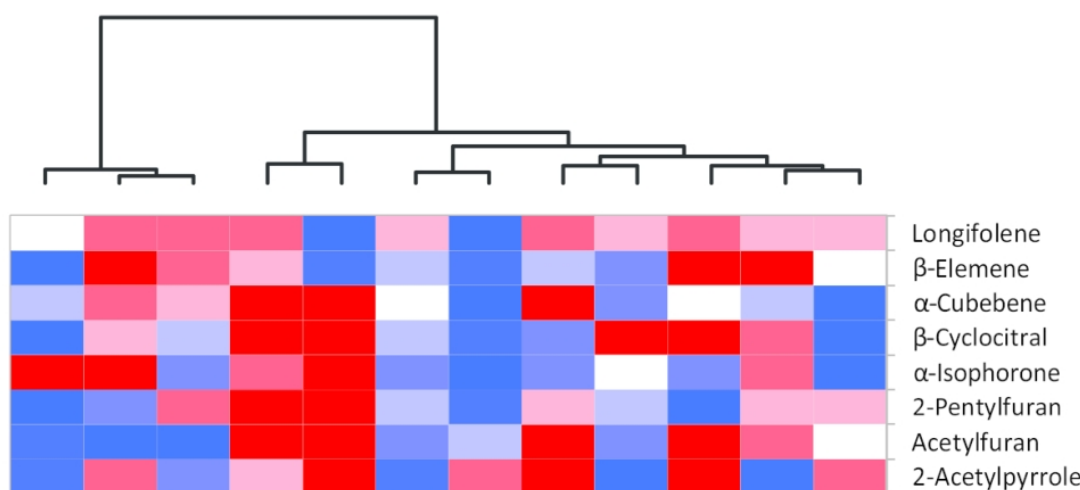

6-Methyl-3,5-heptadiene-2-one

2,2,6-Trimethyl cyclohexanone

6-Methyl-5-hepten-2-one

Ethyl nonanoate

Ethyl octanoate

Ethyl hexanoate

3-Methylbutyl propionate

2-Methylbutyl acetate

Ethyl 2-Methylbutanoate

Ethyl butyrate

Ethyl 2-methylpropanoate

3-Methylbutanoic acid

2-Methylpropanoic acid

Propanoic acid

Phenylethyl Alcohol

Benzylalcohol

6-Methyl-5-hepten-2-ol (95)

2-Methyl-1-propanol

2,5-Dimethylbenzaldehyde

Benzene acetaldehyde

Benzaldehyde

Furfural

Hexanal

3-Methylbutanal

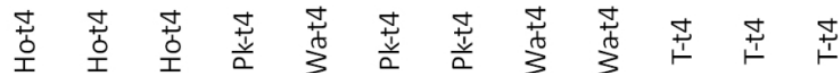

